\title{
CORRELATION OF COVID-19 IN THE ONLINE PURCHASING PROCESS
}

\author{
Saso Josimovski \\ Faculty of Economics - Skopje, Ss. "Cyril and Methodius” University \\ saso.josimovski@eccf.ukim.edu.mk \\ Lidija Pulevska Ivanovska \\ Faculty of Economics - Skopje, Ss. "Cyril and Methodius” University \\ lidija.pulevska@eccf.ukim.edu.mk \\ Martin Kiselicki \\ Faculty of Economics - Skopje, Ss. "Cyril and Methodius" University \\ martin.kiselicki@eccf.ukim.edu.mk \\ Brankica Boceva \\ Digital Present $\mid$ Digital Agency \\ brankica.sk@hotmail.com
}

\begin{abstract}
The paper establishes the central point for researching factors that influence buying decisions in the online purchasing process. The benefits of e-commerce for both buyers and sellers place it as the default method of shopping in the near future. Through empirical research, e-commerce growth is being established as rapidly rising through recent years, which has been accelerated by specific factors introduced by the COVID-19 pandemic. Data shows that e-commerce is dependent on several different factors during normal circumstances, which also include the level of development of the country as one of the main precursors.

The beginning of the COVID-19 pandemic influenced greatly the importance of these established factors for online purchasing, rendering many of them obsolete. The paper structures the research to outline the most relevant factors influencing online purchasing decisions pre-pandemic and during pandemic times, and to draw relevant conclusions and recommendations for future practical implementations of e-commerce models. Research shows that new factors need to be introduce in these types of abnormal times, as the nature of the pandemic made non-contact interactions the norm in the past year. By introducing the six stages of pandemic behavior, online retailers can better understand the factors influencing online purchasing process in pandemic times. Finally, specific recommendations can be made to improve the e-commerce acceptance both at industry and company levels.
\end{abstract}

Keywords: E-commerce, Purchasing process, Buying intent, COVID-19

JEL classification: M30, M31

http://hdl.handle.net/20.500.12188/15921

http://doi.org/10.47063/EBTSF.2021.0009 


\section{INTRODUCTION}

E-commerce has developed a rapid growth in recent years, especially evident during the COVID19 pandemic. Changes in technology are certainly driving the growth of e-commerce, along with global circumstances. Today, in wake of the pandemic, e-commerce must meet consumer expectations for safety and convenience. Examples from practice show increased online purchases during pandemic times (from March 2020 onwards), as businesses notice an influx in e-commerce activity. Companies such as United Parcel Service Inc, are experiencing a pandemic increase in ecommerce to higher profits and a 13\% jump in revenue during the June 2020 quarter. During the same quarter, the company recorded a $65 \%$ increase in deliveries to homes (UPS Investors, 2020). In 2019, Amazon online retail in the US increased by $19.1 \%$ and amounted to over 222.6 billion US dollars (eMarketer, 2021). Figure 1. shows that experts predict that by the end of 2024, online spending will exceed $\$ 476$ billion across the globe (Statista, 2021).

Figure 1. Rise of B2C e-commerce in US from 2017 to 2024

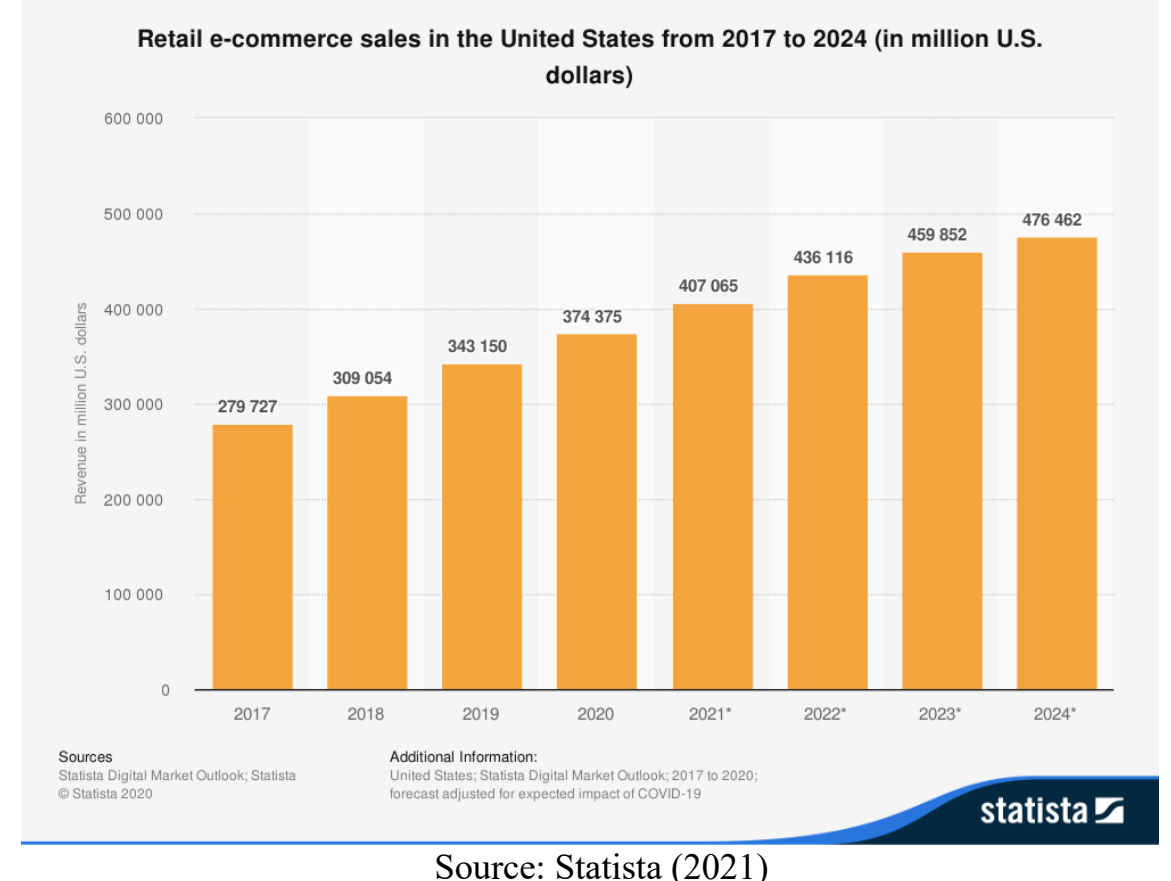

The impact of e-commerce is pervasive and wide-ranging with the effect of rippling from small business to global enterprise.

- Large retailers are forced to sell online;

- E-commerce helps small businesses sell directly to customers;

- Rise of e-commerce markets;

- Supply chain management is evolving;

- New jobs are created, at the expense of that, traditional retail jobs are reduced;

- Social media allows users to easily access and share products for online shopping;

Mobile and other innovations are driving e-commerce into the future and changing its landscape. $90 \%$ of companies now use social media for their business, and many platforms now have custom e-commerce features (Altus Host, 2016). The growth of e-commerce is driven by the rapid technological adaptation led by the increasing use of devices such as smartphones and tablets, and Internet access via broadband, 4G, 5G etc. In terms of highlights, the growth shown by 
corporations like Amazon and Alibaba and the huge investor interest in these and similar companies are a testament for the huge market potential (Keelery, 2020).

The impact of social media on online shopping is extensive. It serves as a vital goal in online marketing by helping companies establish a stronger digital presence, generate leadership and increase traffic (Velayanikal, 2016). A significant percentage of advertising campaigns take place through social media websites. Involving social media in an effort to promote e-commerce can be very rewarding, especially as an effective way to attract the interest of a large audience that uses social media (Chaffey, 2020). Many businesses choose to use the opportunities presented by social media networks to gain more customers.

\section{METHODOLOGY}

For the purposes of the paper, secondary data was used the research the topic. Literature review was used as the main method for obtaining secondary data, including theoretical and background data through books, scientific papers and articles. Theoretical data is obtained through a comprehensive literature review, including books, scientific papers, and articles by relevant authors, dealing with the e-commerce related factors before and during pandemic times.

o The observation method is used for collecting, as well as for researching the literature;

o The historical method is applied when using secondary data sources such as scientific publications, books, empirical studies, reports and articles from the Internet of domestic and foreign literature, which contains topics relevant to the subject of research;

o The paper also uses the method of analysis to analyze all selected materials from domestic and foreign literature, the method of specialization to create their own views based on the read literature and the method of synthesis;

o The inductive and deductive method is used in formulating the conclusions and recommendations and elaborating the working hypotheses;

\section{LITERATURE REVIEW}

There are numerous studies present on online shopping, however there is still a lack of a coherent model for understanding mixed conclusions or findings on online purchasing decisions. Therefore, the findings are most often synthesized in the Online Shopping Acceptance Model (OSAM), which is considered to be the most accurate in predicting consumers' considerations to accept online shopping. This model expands the reference model (Chang et al., 2005) and provides a deeper analysis of the consumption factors associated with online shopping acceptance. Although it is difficult to fully cover all the potential factors and problems, it is still beneficial to include as many findings as possible on the influential consumer factors in accepting online shopping.

Online shopping is a process by which consumers buy goods and services directly from a seller without an intermediary service online. Online shopping has a number of advantages over the traditional shopping process (Chaffey, 2020; Boice, 2020; Prajapati, 2021). There are a set number of factors that are influencing the decision-making process of consumers during the online shopping process, including awareness; trust, security and privacy; availability; perceived price; perceived quality and buying intention.

Awareness is described as a human perception and intellectual response to the state of what is consumed or used (Bashir et al., 2018). Awareness describes the knowledge and information of consumers about the capabilities of a system or technology, its features, potential use, benefits and costs (Abubakar and Ahmed, 2013). In addition, awareness refers to the way it is undertaken to 
procure a product or service. The first step in the buying process is usually considered, in which consumers who are not initially familiar with the product or service become familiar with it (Bashir et al., 2018). In support, Ansari and Alhazemi (2016) report that awareness is the first step in consumer behavior regarding anything that may lead to interest followed by other stages in the buying process. Many studies emphasize that awareness has a positive effect on consumer intent (Abubakar and Ahmed, 2013; Agwu and Murray, 2014; Bashir et al., 2018; Kabango and Asa, 2015; Kiwanuka, 2015; Mohamad and Kassim, 2018). It is important to note that in countries in development, such as the Republic of North Macedonia, there is a lack of awareness and understanding of the potential benefits of online shopping, which is also one of the main obstacles to its acceptance and use.

According to Meyer et al. (1995) trust is described as "a willingness to depend or become vulnerable to the other party when the other party's actions cannot be controlled" (Abdulgani and Suhaimi, 2014). In the history of commerce, trust issues have always been very crucial and have influenced business processes and strategy, brand, organizational structure, including multiple operating practices that go hand in hand in day-to-day business (Abdulgani and Suhaimi, 2014). It is important to note that success in buying and selling on the Internet is predetermined by trust. Trust is also key to building economic relationships, especially in a networked environment, as a result of increased perceptions of doubt and risk (Chiemeke and Evwiekpaefe, 2011). Studies show that consumers' intentions and attitudes towards online shopping have been influenced by trust and perceived benefits of relative advantage (Al-Debei et al., 2015). It has been noted that lack of trust and risk can be the biggest challenge that will prevent many customers from purchasing through Internet channels. In support, Kumar and Bajaj (2019) point out that the perceived risk has a negative impact on online retail. This means that trust is one of the important factors that can easily influence consumer behavior in the use of technology (Faqih, 2016; Saprikins et al., 2018). Trust improves the level of adjustment and acceptance of online transactions. Additionally, trust can enhance customer commitment and satisfaction, which will ultimately lead to loyalty. Trust through the Internet ensures long-term relationships with customers and helps to achieve a competitive advantage. Trust also reduces concerns and fears about consumer information.

Security can be described as the degree to which consumers consider their online payment to be free from unauthorized access, use, alteration and destruction. This may be due to a higher risk of possible fraudulent behavior such as network security breaches where important personal information may be stolen. Thus, security is a major predictor of consumers' intentions to shop online. Security is also a known challenge for online transactions around the world (Tarhini et al, 2015). Hence, the perception of Internet security risk is recognized as a concern for both experienced and inexperienced users of Internet technologies (Kabango and Asa, 2015). Recently, Merhi et al (2019) conducted intercultural research on mobile banking intentions among Lebanese and British clients. They found that the intent of the behavior was influenced by perceived security, perceived privacy, trust and habits of both Lebanese and British mobile banking users. In the same direction, according to the findings of Tarhini et al. (2015) exposed the issue of security that was cited as the main reason why respondents were afraid to accept online banking. In this regard, it must be ensured that online transactions are secure, as well as the protection of consumer privacy by e-commerce web-sites (Kumar and Dange, 2012).

Availability can be described as the degree to which the technology needed for online transactions is readily available to humans (Chiemeke and Evwiekpaefe, 2011). Because the Internet is fast becoming the basis for information and services, a well-structured e-commerce website has become crucial for users to obtain information and expand their involvement. Retail websites can 
also serve as an avenue for communication and customer relations and the general public (Kabango and Asa, 2015).

The term "price" refers to the collection of services through online transactions of customers in relation to transaction costs and savings arising from the effectiveness of e-commerce and financial incentives. As such, transaction costs in the network environment should be low for both the client and the person determining them, especially if micro payments are supported (Chiemeke and Evwiekpaefe, 2011). Price is always a significant issue for consumers in their purchasing decisions. In a study conducted by Olasanmi (2019), the results show that the level of online shopping is negatively correlated with the costs involved. The results also highlight better prices as one of the reasons consumers preferring specific online retailers. In addition, from the work of $\mathrm{Ng}$ et al., (2018) it can be seen that the perceived value has a significant and positive impact on the purchasing intentions of consumers for electric cars. This result is also in line with the findings of Escobar-Rodriguez and Bonson-Fernandez (2017), which indicate the perceived price as one of the key determinants of online consumer clothing purchase in Spain.

Perceived quality is described as the degree to which the product or service meets the needs and expectations of consumers. It is a critical factor that determines customer behavior in the context of online shopping (Ibrahim et al., 2018). A comparative study between Taiwan and Japan conducted by Hsu et al. (2017) identifies the perceived quality of service as one of the key factors influencing the purchasing intentions of consumers in both countries. It has been reported that service quality plays a significant role in ensuring consumer trust in the website (Gao et al., 2015). Therefore, customers are expected to be encouraged to shop online if they recognize the high quality of service that prevails on the website. In support, Liao et al., (2011) point out that the quality of service has a statistically significant effect on the willingness of customers to shop online. Similarly, the findings of Ibrahim, Hassan and Yusuf (2019) show a strong positive relationship between service quality and the consumer's intention to accept online shopping. In addition, the findings of the empirical study of Tarhini et al., (2018) indicate that the intentions of online shoppers in the UK were influenced by the quality of service.

The term buying intentions has received particular attention in recent times and is generally applied to models associated with the adoption and adoption of technology. Behavioral intentions are described as the intentions of an individual to achieve various behaviors (Ajzen, 1991). In other words, intent is defined as "the subjective possibility of individuals that they will commit some behavior" (Saprikins et al., 2018). As such, behavioral intent is seen as a direct precursor to the use of behavior and the indication of individuals' willingness to engage in certain behaviors. Hasan's study (2018) reveals that product attributes and store attributes have a positive effect on the intention to buy. However, Ali and Sudan (2018) points out that the intent of consumer behavior depends on long-term orientation, distance from power, as well as masculinity. A recent study by Nasution et al. (2019) reveals that utility, ease of use, and cost are key factors influencing student shopping intentions. Another research by Aldousari and El-Sayed (2017) reveals that payment options, nationality and the day of the week are the main determinants of consumer behavior intent. Additionally, Eshaghi et al. (2016) conducted an intercultural study, in which they compared the precursors of the intention to shop online among consumers. The results showed that trust in the web-site (based on perceived quality, security and privacy) significantly reflects the frequency of online shopping. 


\section{RESEARCH FINDINGS}

The reality of this new pandemic surprised the world. People are still trying to adapt to the idea of longer stays indoors and social isolation, as well as to avoid shopping in "brick and mortar" stores, ie trying to adapt to the establishment of new and permanent habits (Murillo-Vargas, 2020). Current established factor in the Literature review section no longer influence online purchasing behavior in the same manner through the COVID-19 pandemic. In countries under the strong influence of Covid-19, consumers collected food and other basic items while isolating themselves from the crowd. To find out how and when consumers began to show these behavioral changes, Nielsen Group (2020) conducted a behavioral survey of consumers which started during the beginning. Following trends, consumers go through six stages of behavior based on their awareness of the spread of COVID-19 in their communities:

- Proactive health-oriented shopping: Increased interest in purchasing products that maintain well-being or health;

- "Recreational health" management: Prioritize products for preventing infections (eg. face masks);

- Stocking supplies: Larger purchases of products on the shelves in order to reduce visits to physical stores;

- Preparing to live in isolation: Increased online shopping, reduced store visits and the first signs of a supply chain burden;

- Limited living: Possible price increase due to limited stocks;

- Living a new normal life: Increased health awareness even when people return to their typical daily activities.

At the time of research, China has been the only country that has adopted all six stages of adjustment. The study also found that long-term changes in consumer behavior are likely to be fully anticipated, but it is clear from observed trends that, if maintained, could lead to significant changes in the way we shop in the future. With the spread of the pandemic, it is evident that online shopping has become the first choice of consumers. It is therefore of particular importance to businesses to identify the main factors influencing consumers online during the COVID-19 pandemic.

Research on this topic has shown that the main factors influencing online shopping at the time of the pandemic are quite different from those under normal conditions (Chen et al., 2021). Specifically those key factors such as consumer gender, level of education, price of goods and services, attitudes towards online business services, lack of products and "blind shopping" caused by boredom, which is also confirmed by several studies, that have a significant effect on online shopping under normal circumstances, have failed the significance test. In contrast, the non-contact features of online shopping services, people's opinions about the pandemic situation, the exclusion of offline shopping channels, low-efficiency logistics, official pandemic information and pandemic panic are the main factors influencing online shopping. to the general public in this pandemic (Chen et al., 2021).

From the analysis of the impact factors, it was found that the key factors influencing the online shopping behaviour of the general public during the pandemic differ significantly from those under a normal background. For example, key factors such as gender and level of education that have been shown to have a significant effect on online shopping under a normal background are not significant under an abnormal background. In contrast, the non-contact features of online shopping services are the most important factor influencing online shopping due to the impact of the pandemic. It should be noted that with the gradual improvement of the situation, the influences of 
some factors will decrease, while others will increase, giving a greater effect and will dominate again. Among all the critical impact factors, the non-contact features of online shopping services and the exclusion of offline shopping channels are unique features of this pandemic. The impact of these two features seemed to weaken as the pandemic situation improved, but still, the convenience and other experiences that Internet shopping brings can further influence the general public's choice of online shopping regardless of the variations in the number of patients affected by the pandemic. Hence, while reaping the benefits of the pandemic in the industry, e-commerce companies need to pay more attention to fostering customer loyalty after the pandemic. Other influencing factors during a pandemic include: cost, fast and professional delivery, online retailer brand reputation, and ease of use for website users (Statista, 2021).

\section{CONCLUSIONS}

Pandemic behavior in online shopping has significant differences when applied to online shopping and purchasing decisions. As evident from various studies, established factors influencing online shopping have varying influence, as well as some being rendered completely obsolete. For companies to monitor changes online purchase behavior during pandemic times and adapt accordingly, adjustments have to be made in current factors influencing online purchasing behavior:

- Reputation - reputation is everything, and online e-commerce platforms provide the perfect opportunity to communicate with customers and solve their problems in a fast way. During pandemic times, companies are exposed to new customers who may solely base their purchasing decision on the reputation of the company.

- Delivery times - Focusing on the 4Ps, place is the single attribute that is being completely digitalized, as consumers replace their visits to physical stores with online shopping. During traditional shopping the consumer has the product right after payment, so reducing delivery times should be one of the company top priorities.

- Monitor stages of behavior - as pointed by the Nielsen group, consumers go through six stages of changes in their online purchasing behavior. Companies need to monitor the stage the customers are in, so they can adapt their marketing strategies, as well as anticipate changes in demand based on the next stages.

- Brand personality - Since online shopping is non-contact, the social media channels and web-site of a company become the only point of interaction with the consumers. Thus, it is becoming more important than ever for businesses to have a strong voice and deal with customers on a human level.

- Digitalized products or services - one of the main players during pandemic times are products or services in digital form, making them instantly accessible across the world without any delivery times. Companies need to adapt (within industry boundaries) to deliver products and services solely through Internet channels.

- Security and privacy - in countries with low e-commerce participation, security and privacy are one of the main precursors for failed online shopping initiatives. By focusing on the payment system as a whole (or using third party providers trusted by consumers), companies can positively influence e-commerce adoption.

The paper gives an overview of the main factors influencing e-commerce adoption, as well as their significance in abnormal times. This research can be expanded further with focus on countries in development, where the general levels of e-commerce adoption were low before pandemic times. 
Additionally, the research can be updated after the pandemic period is over, to see whether increased e-commerce adoption level will continue steadily or decline.

\section{REFERENCES}

Abdulgani, M.A. and Suhaimi, M.A. (2014) 'Exploring factors influence Muslim intention to purchase online', $5^{\text {th }}$ International Conference on Information and Communication Technology for the Muslim World (ICT4M), pp.1-6. Abubakar, F.M. and Ahmed, H.B. (2013) 'The moderating effect of technology awareness on the relationship between UTAUT constructs and behavioral intention to use technology: A conceptual paper', Australian Journal of Business and Management Research, 3(2), pp.14-23.

Agwu, E. and Murray, P.J. (2014) 'Drivers and inhibitors to e-Commerce adoption among SMEs in Nigeria', Journal of Emerging Trends in Computing and Information Sciences, 1(3), pp.18-24.

Ajzen, I. (1991) 'The Theory of Planned Behavior', Organizational Behavior and Human Decision Processes, 50(2), pp. 179-211.

Akroush, M.N. and Al-Debei, M.M. (2015) 'An integrated model of factors affecting consumer attitudes towards online shopping', Business Process Management Journal, 21(6), pp.1353-1376.

Ali, S.W. and Sudan, S. (2018) 'Influence of cultural factors on impulse buying tendency: A study of Indian consumers', Vision, 22(1), pp.68-77.

Al-Debei, M.M., Akroush, M.N. and Ashouri, M.I. (2015) 'Consumer attitudes towards online shopping: the effects of trust, perceived benefits, and perceived web quality', Internet Research, 25(5), pp. 707-733.

Aldousari, A.A. and El-Sayed, I.M. (2017) 'Factors influencing consumers' patronage intentions in Kuwait', Journal of Business and Retail Management Research, 11(3).

Ansari, Z.A. and Alhazemi, A. (2016) 'An Empirical Study of the Consumer Awareness and Acceptance of Online Shopping in Saudi Arabia', Internet Journal of Development Research, 6(2), pp. 6918-6925.

Bashir, A.M., Bayat, A., Olutuase, S.O. and Abdul Latiff, Z.A. (2018) 'Factors affecting consumers' intention toward purchasing halal food in South Africa: a structural equation modelling', Journal of Food Products Marketing, 25(1), pp.26-48.

Boice, M.(2020) 'The 13 Top Reasons Consumers Shop Online'. JungleScout, 17 November. Available at: https://www.junglescout.com/blog/reasons-consumers-shop-online/(Accessed: 10 October 2021).

Chang, M.K., Cheung, W. and Lai, V.S. (2005) 'Literature Derived Reference Models for the Adoption of Online Shopping', Information and Management, 42, pp. 543-559.

Chaffey, D. (2020) 'Global social research summary 2021', Smart Insights, 11 March. Available at:

https://www.smartinsights.com/social-media-marketing/social-media-strategy/new-global-social-media-research/

(Accessed: 19 August 2021).

Chiemeke, S.C. and Evwiekpaefe, A.E. (2011) 'A conceptual framework of modified unified theory of acceptance and use of technology (UTAUT) Model with Nigerian factors in E-commerce adoption', Educational Research, 2(12), pp.1719-1726.

Chen, Y., Guang-Wen, Z., Abu Bakkar, S., Quan Li, D. and Chang, D. (2021) 'Factors Affecting the Consumers Online Shopping During the COVID-19 Pandemic in China', Revista Argentina de Clinica Psicologica, 30(1), pp. 853-864.

Escobar-Rodriguez, T. and Bonson-Fernandez, R. (2017) ‘Analyzing online purchase intention in Spain', Journal of Information Systems and e-Business Management, 15(3), pp.599-622.

Eshaghi, S.M.S., Afshardoost, M. and Ahmadi, M.M. (2016) 'Antecedents of online purchase intention: A crossnational study between Iran and Malaysia', In $10^{\text {th }}$ International Conference on e-Commerce in Developing Countries - with focus on e-Tourism (ECDC), pp.1-13.

Faqih, K.M.S. (2016) 'An empirical analysis of factors predicting the behavioral intention to adopt Internet shopping technology among non-shoppers in a developing country context: Does gender matter?', Journal of Retailing and Consumer Services, 30, pp. 140-164.

Gao, L., Waechter, K.A. and Bai, X. (2015) 'Understanding consumers' continuance intention towards mobile purchase: A theoretical framework and empirical study - A case of China', Computers in Human Behavior, 53(9), pp. 249-262.

Hasan, A. (2018) 'Impact of store and product attributes on purchase intentions: An analytical study of apparel shoppers', Vision, 22(1), pp. 32-49. 
Hsu, C.L., Chen, M.C., Kikuchi, K. and Machida, I. (2017) 'Elucidating the determinants of purchase intention toward social shopping sites: A comparative study of Taiwan and Japan', Telematics and Informatics, 34(4), pp. 326-338.

Ibrahim, A.M., Hassan, M.S. and Gusau, A.L. (2018) 'Factors Influencing Acceptance and Use of ICT Innovations by Agribusinesses', Journal of Global Information Management (JGIM), 26(4), pp. 113-134.

Kabango, C.M. and Asa, R. (2015) 'Factors influencing e-commerce development: Implications for the developing countries', ResearchGate, 1(1), pp.64-72.

Keelery, S. (2020) 'E-commerce in India - statistics and facts', Statista, 04 August. Available at:

https://www.statista.com/topics/2454/e-commerce-in-india/ (Accessed: 19 August 2021).

Kiwanuka, A. (2015) 'Acceptance process: The missing link between UTAUT and diffusion of innovation theory', American Journal of Information Systems, 3(2), pp. 40-44.

Kumar, P. and Bajaj, R. (2019) 'Exploring the influence of demographic factors on perceived performance risk among youth towards online shopping', International Journal of Business and Globalisation, 23(1), pp. 47-68.

Kumar, V. and Dange, U. (2012) 'A study of factors affecting online buying behavior: A conceptual model'. Ujwala, A Study of Factors Affecting Online Buying Behavior: A Conceptual model (25 August).

Liao, Z. and Cheung, M.T. (2001) 'Internet-Based E-Shopping and Consumer Attitudes an Empirical Study', Information and Management, 38(5), pp. 299-306.

Meyer, R.C., Davis, J.H. and Schoorman, F.D. (1995) 'An Integrative Model of Organizational trust', The Academy of Management Review, 20(3), pp. 709-734. [Online] Available at:

https://www.jstor.org/stable/258792?seq=1\#metadata info tab contents (Accessed: 29 July 2021).

Merhi, M., Hone, K. and Tarhini, A. (2019) 'A cross-cultural study of the intention to use mobile banking between Lebanese and British consumers: Extending UTAUT2 with security, privacy and trust', Technology in Society, 59, pp. 1-12.

Mohamad, S.A. and Kassim, S. (2018) 'Examining the Relationship between UTAUT Construct, Technology Awareness, Financial Cost and E-Payment Adoption among Microfinance Clients', In $1^{\text {st }}$ Aceh Global Conference (AGC 2018).

Murillo-Vargas, D. (2020) 'How the COVID-19 Pandemic is Influencing Consumer Behavior', Contentserv, 26 March. Available at: https://www.contentserv.com/en/blog/how-covid-19-pandemic-is-influencing-consumerbehavior/ (Accessed: 11 August 2021).

Nasution, M.D.T.P., Rossanty, Y., Ariffin, K.H.K., and Zaini, N.I.B.M. (2019) 'An empirical examination of the factors influencing consumer's purchase intention toward online shopping', Journal of Business and Retail Management Research, 13(4), pp. 1-12.

Ng, M., Law, M. and Zhang, S. (2018) 'Predicting purchase intention of electric vehicles in Hong Kong', Australian Marketing Journal (AMJ), 26(3), pp. 272-280.

Olasanmi, O.O. (2019) 'Online shopping and customers' satisfaction in Lagos state, Nigeria', American Journal of Industrial and Business Management, 9, pp. 1446-1463.

Prajapati, V.(2021) Why Do People Shop Online? - Top 10 Reasons You Can't Ignore. Available at: https://www.techprevue.com/reasons-prefer-online-shopping/ (Accessed: 10 October 2021).

Saprikins, V., Markos, A., Zarmopou, T. and Vlachopoulou, M. (2018) 'Mobile shopping consumers' behavior: An exploratory study and review', Journal of theoretical and applied electronic commerce research, 13(1), pp. 71-90. Tarhini, A., Mgbemena, C., Trab, M.S.A. and Masa'Deh, R. (2015) 'User adoption of online banking in Nigeria: A qualitative study', The Journal of Internet Banking and Commerce, 20(3).

Velayanikal, M. (2016) 'The latest numbers on web, mobile, and social media in India (Infographic)', TechInAsia, 06 September. Available at: https://www.techinasia.com/india-web-mobile-data-series-2016 (Accessed: 17 August 2021).

\section{Online sources}

AltusHost, (2016) Available at: https://www.altushost.com/the-history-of-e-commerce-online-shopping-evolutionand-buyers-behaviour/ (Accessed: 23 July 2021).

eMarketer (2021) Available at: https://www.emarketer.com/chart/234148/amazon-us-retail-ecommerce-sales-20172021-billions-change-of-us-retail-ecommerce-sales-sales (Accessed: 23 July 2021).

NielsenIQ (2020) Available at: https://nielseniq.com/global/en/insights/analysis/2020/a-guide-to-winning-in-storein-2021/(Accessed: 11 August 2021).

Statista, (2020) Available at: https://www.statista.com/statistics/272391/us-retail-e-commerce-sales-forecast/ (Accessed: 23 July 2021). 
UPS Investors (2020) Available at: http://www.investors.ups.com/news-releases/news-release-details/ups-releases2q-2020-earnings\#: :text=UPS\%20(NYSE\%3AUPS)\%20today,the $\% 20$ same $\% 20$ period $\% 20$ in $\% 202019$ (Accessed: 20 July 2021). 